\title{
O Empreendedorismo Social no Brasil: quem são e o que Fazem
}

\section{Social Entrepreneurship in Brazil: Who they are and What They do}

\author{
Wesley Osvaldo Pradella Rodriguesa ; José Francisco dos Reis Neto ; Pablo Antonio Muñoz Gallego \\ Alan Francisco Dos Santos ${ }^{\mathrm{b}}$ \\ ${ }^{a}$ Universidade Federal de Mato Grosso do Sul. MS, Brasil. \\ bUniversidade Anhanguera Uniderp, Programa de Pós-Graduação Stricto Sensu em Meio Ambiente e Desenvolvimento Regional. MS, Brasil. \\ 'Instituto Multidisciplinar de La Empresa. Departamento de Administración Y Economía de La Empresa. Espanha. \\ ¿Universidad de Salamanca, Espanha. \\ *E-mail: wesley.rodrigues@ufms.br
}

\begin{abstract}
Resumo
Empreendedorismo social é visto como uma forma hibrida de empreendedorismo, no qual se prioriza a promoção do valor social e desenvolvimento versus a captura de valor econômico. Este artigo objetiva analisar o perfil do Empreendedor Social (ES) no Brasil, e as diferenças em destaque com o tipificado Empreendedor voltado para o Mercado (EM). Foram utilizados os dados secundários obtidos junto ao GEM Adult Population Survey (APS) 2015/16. A amostra foi constituída por 2000 empresários adultos em atividade, escolhidos de forma probabilística com base no censo brasileiro e, posteriormente, separados em dois grupos, conforme proposto no objetivo. A fim de explorar as diferenças entre estes dois grupos se empregou o teste do qui-quadrado para amostras independentes não paramétricas, utilizando o software SPSS v.25. Os resultados apresentam o perfil dos empreendedores sociais analisados sob as dimensões Atitudes e Percepções Empreendedoras; Atividade Empreendedora e Aspirações Empreendedoras. Apesar de constituir uma pequena parcela empresarial brasileira se concluiu que o empreendedor social se diferencia do empreendedor para o negócio em relação as suas características de conhecimento e habilidade para o negócio social, de analisar e assumir os riscos calculados e proporcionar ideias inovadoras. Ao avaliar o perfil do empreendedor social brasileiro se espera ampliar o conhecimento acadêmico e de negócio, ao identificar os aspectos que diferenciam os empreendedores sociais dos empreendedores voltados para o mercado, possibilitando o delineamento de estudos futuros sobre a temática apresentada.
\end{abstract}

Palavras-chave: Atividade do Empreendedorismo Social. Empreendedorismo Híbrido. Global Entrepreneurship Monitor.

\begin{abstract}
Social entrepreneurship is seen as a hybrid form of entrepreneurship, in which the social value promotion and development is prioritized versus the economic value capture. This article aims to analyze the Social Entrepreneur's profile (SE) in Brazil, and the differences highlighted with the typified Market-oriented Entrepreneur (ME). Secondary data from the GEM Adult Population Survey (APS) 2015/16 were used. The sample consisted of 2000 active adult entrepreneurs, selected in a probabilistic manner based on the Brazilian census and later separated into two groups, as proposed in the objective. In order to explore the differences between these two groups, the chi-square test was used for nonparametric independent samples using the SPSS v.25 software. The results present the social entrepreneurs's profile analyzed under the dimensions Entrepreneurial Attitudes and Perceptions; Entrepreneurial Activity and Entrepreneurial Aspirations. Despite constituting a small portion of Brazilian business, it was concluded that the social entrepreneur differs from the market-oriented entrepreneur in terms of knowledge and skill for social business, to analyze and take calculated risks and provide innovative ideas. By assessing the Brazilian social entrepreneur's profile, it is expected to broaden academic and business knowledge by identifying the aspects that differentiate social entrepreneurs from market-oriented entrepreneurs, enabling the design of future studies on the theme presented.
\end{abstract}

Keywords: Social Entrepreneurship Activity. Hybrid Entrepreneurship. Global Entrepreneurship Monitor.

\section{Introdução}

Empreendedorismo social é visto como uma forma hibrida de empreendedorismo, no qual se prioriza a promoção do valor social e desenvolvimento versus a captura de valor econômico. Entretanto, este conceito se apresenta em desenvolvimento na literatura e seus limites para os demais campos de estudos ainda se mostram confusos, assim como a identificação de seus empreendedores.

Dees (1998) define empreendedorismo social (ES) como um processo inovador, no qual resulta em um impacto social. Nesta perspectiva, o autor ressalta que a atenção é voltada para a inovação e organizações sociais, muitas vezes, deixando de lado a busca por retornos financeiros. Para Carraher e
Welsh (2015), empreendedorismo social é o processo que envolve a inovação na combinação de recursos para buscar oportunidades que desencadeiam mudanças sociais e atendam às necessidades sociais. Mair e Martí (2006) compreendem o empreendedorismo social como um processo que envolve o uso inovador e a combinação de recursos para buscar oportunidades de catalisar mudar e/ou atender às necessidades sociais.

Segundo Alvord, Brown e Letts (2004), empreendedorismo social é um processo que cria soluções inovadoras para problemas sociais imediatos e mobiliza ideias, capacidades, recursos e acordos sociais necessários para essa transformação social sustentável. Para Austin e Skillern (2006), empreendedorismo social é compreendido como uma 
atividade de criação de valor social inovadora, a qual pode ocorrer dentro ou entre setores sem fins lucrativos, comerciais ou governamentais.

Oliveira (2004) destaca que o empreendedorismo social, antes de tudo, se trata de uma ação inovadora voltada para o campo social, e apresenta características fundamentais, tais como: i) ser inovadora; ii) ser realizável; iii) ser autossustentável; iv) envolver várias pessoas e segmentos da sociedade; e v) promover impacto social. O Global Entrepreneurship Monitor (GEM) define empreendedorismo social como qualquer tentativa de nova atividade de criação de empresa ou expansão de empreendimento com objetivos sociais ou comunitários, em que o lucro é investido na atividade ou próprio empreendimento, em vez de ser devolvido aos investidores (HARDING, 2006).

Assim como Certo e Miller (2008) se podem destacam dois pontos importantes sobre as definições. Primeiro, as definições destacam o papel da inovação, ou seja, empreendedorismo social envolve a aplicação de uma nova tecnologia ou abordagem no esforço de criar valor social, assemelhando com a visão schumpeteriana de empreendedorismo, no qual se ressalta o papel da inovação no empreendedorismo. Então, empreendedores sociais podem ser vistos como inovadores sociais, conforme explicam Certo e Miller (2008). Segundo, o empreendedorismo social pode envolver empreendedores individuais, organizações sem fins lucrativos ou não, novas ou existentes ou governos.

Os empreenderes sociais vem desempenhando um importante papel para a melhoria das condições sociais, em especial, em economias subdesenvolvidas e emergentes, nas quais há escassez de recursos e corrupção na estrutura do Estado (ZAHRA et al., 2009; FERREIRA et. al. 2017). Os empreendedores sociais também se mostram como agentes de mudança do desenvolvimento de um país, quando aplicam métodos e estratégias inovadoras e de baixo custo na resolução de problemas sociais (COX; HEALEY, 1998).

Diante disto, a seguinte questão norteou a realização do estudo: existem diferenças de perfil empreendedor entre empreendedores sociais e empreendedores voltados para o mercado e quais são essas diferenças. Essas questões conduziram para o objetivo deste estudo, que se consiste em analisar o perfil do Empreendedor Social (ES) no Brasil, e as diferenças em destaque com o tipificado Empreendedor voltado para o Mercado (EM), utilizando como os dados da pesquisa realizada em 2015 e 2016, pelo GEM, contendo dados especiais sobre as características de empreendedorismo social e de negócio.

Neste contexto, a relevância do estudo reside na possibilidade de identificar aspectos que diferenciam os empreendedores sociais dos empreendedores voltados para o mercado, em relação às atitudes e percepções, atividade e aspirações empreendedoras, e que possam contribuir para a abertura e manutenção desses empreendimentos.
A respeito do perfil empreendedor, foi utilizado como suporte aos aspectos utilizados pelo GEM, o qual o divide em três dimensões: (i) atitudes e percepções empreendedoras, (ii) atividade empreendedora; e (iii) aspirações empreendedoras (BOSMA et. al., 2009). A dimensão "atitudes e percepções empreendedoras" expressa o sentimentogeral dapopulação para os empresários e empreendedorismo, se as atitudes em relação ao empreendedorismo são positivas, isso gerará um apoio ambiente para startups e crescimento do empreendedorismo. A dimensão "atividade empreendedora" pode ser definida como o que os empreendedores fazem, concentrando-se em medidas em que os indivíduos estão criando novos negócios. A dimensão "aspirações empreendedoras" se concentra nas perspectivas de crescimento dos empreendimentos e na disponibilidade de financiamento para o crescimento, além de mensurar o desenvolvimento de produtos inovadores, o uso de tecnologia de ponta e o potencial de exportação (SZERB et al., 2013).

\section{Material e Métodos}

Utilizando a estrutura considerado pelo Global Entrepreneurship Monitor (GEM) 2015/16 Global Report (Bosma et. al., 2016), foram analisadas as medidas individuais de Atitudes, Atividades e Aspirações Empreendedoras no Brasil, dados secundários obtidos junto ao GEM Adult Population Survey (APS) 2015/16. As variáveis analisadas são apresentadas no Quadro 1.

Quadro 1 - Variáveis analisadas no trabalho

\begin{tabular}{|c|c|}
\hline Dimensão & Medidas \\
\hline \multirow{6}{*}{$\begin{array}{c}\text { Atitudes e } \\
\text { Percepções } \\
\text { Empreendedoras }\end{array}$} & Percepção de oportunidade \\
\hline & Percepção de capacidade \\
\hline & Medo de falhar \\
\hline & Intenção empreendedora \\
\hline & Empreendedorismo como opção de carreira \\
\hline & Atenção da mídia ao empreendedorismo \\
\hline \multirow{5}{*}{$\begin{array}{c}\text { Atividade } \\
\text { Empreendedora }\end{array}$} & Atividade empreendedora nascente \\
\hline & Proprietário/gerente de novos negócios \\
\hline & $\begin{array}{l}\text { Atividade empreendedora em estágio } \\
\text { inicial }\end{array}$ \\
\hline & Taxa geral de atividade empresarial \\
\hline & Taxa de descontinuação de negócios \\
\hline \multirow{4}{*}{$\begin{array}{c}\text { Aspirações } \\
\text { Empreendedora }\end{array}$} & $\begin{array}{l}\text { Expectativa de alto crescimento em } \\
\text { atividade empreendedora em estágio inicial }\end{array}$ \\
\hline & $\begin{array}{l}\text { Atividade empreendedora em estágio } \\
\text { inicial de alta expectativa de crescimento: } \\
\text { prevalência relativa }\end{array}$ \\
\hline & $\begin{array}{l}\text { Nova atividade empreendedora em estágio } \\
\text { inicial orientada para o mercado de } \\
\text { produtos: prevalência relativa. }\end{array}$ \\
\hline & $\begin{array}{l}\text { Atividade empreendedora inicial nos } \\
\text { setores de tecnologia: prevalência relativa. }\end{array}$ \\
\hline
\end{tabular}

Fonte: Adaptado de Bosma et al. (2009) e Szerb et. al. (2013). 
O GEM entrevistou 2000 empresários adultos que estavam começando e/ou liderando algum tipo de atividade, organização ou iniciativa empresarial na qual tinham uma característica social, ambiental, comunitária ou empresarial no Brasil durante o ano de 2015. O GEM é uma iniciativa global no qual possui o objetivo de facilitar uma comparação entre países das atividades empreendedoras, por meio da utilização do mesmo instrumento de avaliação, com amostras representativas da população de pelo menos 2.000 adultos selecionados, aleatoriamente, em cada país participante, considerando o seu censo empresarial (BOSMA et. al., 2016).

Classificou-se a amostra em dois grupos: Empreendedorismo Social(ES) e Empreendedorismos Voltado para o Mercado (EM). A variável considerada na classificação dos empresários ES ou EM foi: "Você está sozinho ou com outras pessoas, atualmente, tenta iniciar ou liderar algum tipo de atividade que tenha um objetivo social, ambiental ou comunitário?". Esta variável dicotômica deu condição de classificar a atividade empresarial que possa ser qualquer forma de trabalho social ou comunitário, incorporado ou não, com ou sem fins lucrativos, capturando todos os indivíduos envolvidos em uma organização com o objetivo de abordar uma questão social (LEPOUTRE et al., 2013).

Com base no critério utilizado, dois grupos foram obtidos e classificados como: ES com 56 empresários e EM com 1.944 empresários. Para explorar as possíveis diferenças entre estes dois grupos, as três dimensões categóricas escolhidas (Quadro 1), foi empregado o teste do qui-quadrado para amostras independentes não paramétricas, utilizando o software SPSS v. 25 .

\section{Resultados e Discussão}

O Quadro 2 apresenta o perfil dos empreendedores em termos de gênero, idade, educação. Os ES no Brasil são, em sua maioria do sexo masculino $(57,1 \%)$ em comparação aos empreendedores voltados para os negócios (48,8\%). Em resumo, os ES são mais propensos a possuírem mais de 35 anos $(71,4 \%)$; possuir maior nível de escolaridade e operam o negócio em regime de tempo integral. Os empreendedores voltados para os negócios são mais novos (18-34 anos), possuem alta probabilidade de possuírem apenas o Ensino Médio e, assim como os ES, dedicam a tempo integral em seus negócios.

Quadro 2 - Características diferenciadoras entre Empreendedorismo Social (ES) e Empreendedorismo voltado para o Mercado (EM) no Brasil, 2015

\begin{tabular}{|c|l|c|c|}
\hline Aspectos & \multicolumn{1}{|c|}{ Variáveis } & ES (\%) & EM (\%) \\
\hline \multirow{3}{*}{ Gênero } & Masculino & 57,1 & 48,8 \\
\cline { 2 - 4 } & Feminino & 42,9 & 51,2 \\
\hline \multirow{4}{*}{ Idade } & $18-24$ & 16,1 & 19,3 \\
\cline { 2 - 4 } & $25-34$ & 12,5 & 26,6 \\
\cline { 2 - 4 } & $35-44$ & 26,8 & 22,6 \\
\cline { 2 - 4 } & $45-54$ & 33,9 & 18,3 \\
\cline { 2 - 4 } & $55-64$ & 10,7 & 13,1 \\
\hline
\end{tabular}

\begin{tabular}{|l|l|c|c|}
\hline Aspectos & \multicolumn{1}{|c|}{ Variáveis } & ES (\%) & EM (\%) \\
\hline \multirow{4}{*}{ Educação } & $\begin{array}{l}\text { Educação } \\
\text { Infantil }\end{array}$ & 1,8 & 1,7 \\
\cline { 2 - 4 } & Ensino Básico & 3,6 & 26,5 \\
\cline { 2 - 4 } & Ensino Médio & 14,3 & 19,5 \\
\cline { 2 - 4 } & Ensino Superior & 51,8 & 44,5 \\
\cline { 2 - 4 } & Pós-Graduação & 28,6 & 7,7 \\
\hline \multirow{3}{*}{$\begin{array}{l}\text { Status de } \\
\text { Trabalho }\end{array}$} & Tempo Integral & 76,8 & 66,8 \\
\cline { 2 - 4 } & Tempo Parcial & 12,5 & 4,9 \\
\cline { 2 - 4 } & Outros & 10,7 & 28,3 \\
\hline Total & & 56 & 1944 \\
\hline
\end{tabular}

Fonte: Dados da pesquisa.

Destaca-se, ainda, a aplicação do teste de qui-quadrado para estas variáveis, não se observaram diferenças significativas a $\mathrm{p}<0,05$ para os grupos ES e EM com relação às variáveis da dimensão gênero, idade, educação e status de trabalho.

O Quadro 3 apresenta resultados de frequência para as variáveis relacionadas à dimensão "Atitudes e Percepções Empreendedoras" entre os grupos de empresários classificados como ES e EM. Destaca-se que o valor porcentual está relacionado à aceitação positiva para a declaração oferecida.

Quadro 3 - Atitudes e Percepções Empreendedoras no Brasil em 2015

\begin{tabular}{|l|c|c|}
\hline $\begin{array}{l}\text { Atitudes e Percepções Empreendedoras } \\
\text { (variáveis) }\end{array}$ & $\begin{array}{c}\text { ES } \\
\text { (\%) }\end{array}$ & $\begin{array}{c}\text { EM } \\
\text { (\%) }\end{array}$ \\
\hline $\begin{array}{l}\text { Vê boas oportunidades para iniciar um negócio } \\
\text { nos próximos 6 meses? }\end{array}$ & 42,9 & 42,6 \\
\hline $\begin{array}{l}\text { Possui o conhecimento e as habilidades } \\
\text { necessárias para iniciar um negócio? }\end{array}$ & 73,2 & 59,4 \\
\hline $\begin{array}{l}\text { O medo do fracasso impediria iniciar um } \\
\text { negócio? }\end{array}$ & 30,4 & 50,5 \\
\hline $\begin{array}{l}\text { Espera iniciar um negócio nos próximos 3 } \\
\text { anos? }\end{array}$ & 37,5 & 23,8 \\
\hline $\begin{array}{l}\text { Conhece pessoalmente alguém que iniciou um } \\
\text { negócio nos últimos 2 anos? }\end{array}$ & 80,4 & 78,3 \\
\hline $\begin{array}{l}\text { Empreendedorismo considerado como opção } \\
\text { de carreira? }\end{array}$ & 87,5 & 80,3 \\
\hline Atenção da mídia ao empreendedorismo & 75,0 & 69,9 \\
\hline
\end{tabular}

Fonte: Dados da pesquisa.

Para a verificação de diferenças significativas entre os grupos de empresários ES e EM, utilizando o teste estatístico do qui-quadrado para independência de amostras categóricas, foram encontrados os seguintes valores para as variáveis: "Possui o conhecimento e habilidades necessárias para iniciar um negócio", $X^{2}(1,1978)=5,310, \mathrm{p}=0,021$; "O medo do fracasso impediria iniciar um negócio", $X^{2}(1,1986)=7,072$, $\mathrm{p}=0,008$; e "Espera iniciar um negócio nos próximos 3 anos", $X^{2}(1,1958)=5,820, \mathrm{p}=0,016$; são estatisticamente diferentes a $\mathrm{p}<0,05$. Pode-se inferir que os empresários sociais empregam mais o conhecimento e habilidades para iniciar o negócio, têm mais crença no sucesso empresarial, e esperam abrir uma nova empresa dentro de três anos.

As duas últimas variáveis do Quadro 3 medem as atitudes nacionais em relação ao empreendedorismo, e ambas não possuem diferenças significativas $(p<0,05)$ entre 
os grupos ES e EM. O empreendedorismo é identificado como uma oportunidade de negócio, tanto para o ES como para o EM, indicando que estes sentiam que no Brasil, o empreendedorismo é considerado uma escolha de carreira desejável. A variável que diz respeito à atenção dada ao empreendedorismo e cobertura da mídia para novos negócios no Brasil, quase na mesma intensidade para os dois grupos, como percebido pelos respondentes.

Estes resultados podem ser suportados por Bosma et al. (2009), em que destacam a importância das atitudes empreendedoras por expressarem o sentimento geral da sociedade em relação aos empreendedores e ao empreendedorismo. Para Szed et al. (2013), atitudes positivas estão relacionadas às elevadas taxas de startup, e destacam ainda que, pessoas com "atitudes empreendedoras" positivas tendem a ser também pessoas que reconhecem oportunidades. Além disso, se as atitudes nacionais em relação ao empreendedorismo forem positivas, isso gerará um ambiente favorável às startups e ao crescimento do empreendedorismo. Bosma et al. (2016) destacam que em países classificados como "Efficiency-Driven Economies", como o caso do Brasil, o Governo deveria manifestar mais apoio para essas atividades empreendedoras.

A partir da elevada taxa de afirmação, por parte dos ES, sobre possuírem conhecimento e habilidades necessárias para o início de um empreendimento, e a baixa taxa em percepção de medo de falência, pode-se considerar que a percepção de boas oportunidades de negócios alinhada com o conhecimento e habilidades necessárias para a abertura de um empreendimento, reduz a percepção de medo de falência por parte dos empreendedores sociais.

A segunda dimensão analisa a atividade empreendedora. $\mathrm{O}$ exame de múltiplos componentes da atividade empreendedora permite explorar as diferenças dos estágios empresariais, entre os grupos ES ou EM, o Quadro 4 apresenta as variáveis analisadas na Atividade Empreendedora.

Quadro 4 - Atividade Empreendedora no Brasil em 2015

\begin{tabular}{|l|c|c|}
\hline $\begin{array}{l}\text { Atividade Empreendedora } \\
\text { (variáveis) }\end{array}$ & ES & EM \\
\hline Atividade empreendedora nascente & $0,0 \%$ & $10,8 \%$ \\
\hline Proprietário/gerente de novos negócios & $37,5 \%$ & $34,8 \%$ \\
\hline $\begin{array}{l}\text { Atividade empreendedora em estágio } \\
\text { inicial (TEA) }\end{array}$ & $19,6 \%$ & $14,6 \%$ \\
\hline Taxa geral de atividade empresarial & $30,4 \%$ & $20,0 \%$ \\
\hline Taxa de descontinuação de negócios & $8,9 \%$ & $18,5 \%$ \\
\hline
\end{tabular}

Fonte: Dados da pesquisa.

A taxa de atividade empreendedora em estágio inicial (TEA) representa a proporção de pessoas que estão envolvidas na atividade empreendedora tanto como novos empreendedores ou como proprietário/gerente de um novo empreendimento.

Para a verificação de diferenças significativas entre os empreendedores sociais e de mercado, por meio do quiquadrado, se encontrou que a variável taxa de descontinuação de negócios, $X^{2}(1,829)=4,716, p=0,030$. A descontinuação de negócios é uma característica importante em uma economia dinâmica, sob os efeitos da micro e macroeconomia, em que o Brasil passou nos últimos anos. Como observado no Quadro 4, o grupo EM apresentaram taxa de descontinuação duas vezes maiores que o grupo ES. Dentro dos principais motivos relacionados à descontinuidade dos empreendimentos no Brasil se pode estar associado ao que o Sebrae (2016) destaca como problema relacionado ao: i) planejamento, ii) capacitação e iii) gestão.

A terceira dimensão analisada se refere à aspiração empreendedora, a qual reflete a natureza qualitativa da atividade empreendedora. As aspirações podem ser entendidas como a introdução de novos produtos, novos processos de produção, engajar-se em mercados estrangeiros, desenvolver uma organização significativa e financiar o crescimento com capital externo. Essas aspirações, se forem realizadas, podem afetar, significativamente, o impacto econômico dessas atividades empresariais. As medidas que capturam essas aspirações podem ser observadas no Quadro 1.

A variável Expectativa de alto crescimento em atividade empreendedora, em estágio inicial, busca quantificar quantos empreendedores esperam expandir o número de funcionários nos próximos cinco anos. Nesse aspecto, apenas o grupo EM apresentou essa aspiração, 0,5\% dos entrevistados. Pesquisa realizada em 2016, pelo GEM (2017), apresenta taxa de expectativa de crescimento de $3,0 \%$, o aumento da expectativa de se relaciona ao momento de mudanças políticas vivenciadas pelo país aliado como o desempenho econômico positivo, apesar de baixo. Quando questionado sobre a criação de mais de 20 empregos, 1,3\% esperavam em 2016, já na pesquisa de 2015, os entrevistados responderam de forma negativa.

O GEM (2017) considera a inovação nos novos empreendimentos por meio da avaliação sobre a novidade (ou falta de familiaridade) de seus produtos ou serviços em relação à expectativa atual dos clientes. Em essência, busca mensurar a porcentagem de novos empreendedores, que oferecem produtos ou serviços, os quais eles acreditam serem novos para os consumidores e/ou que há poucos ou inexistente concorrência para os mesmos produtos. Os dados revelam que os ES apresentam maior taxa de inovação $(1,8 \%)$ em comparação com os EM (1,0\%). Grande parte dos ES não apresentam inovação (14,3\%) (empreendedores voltados para o mercado $3,8 \%$ ).

De forma complementar, o GEM pondera a inovação de produtos e processos, a internacionalização e a ambição por alto crescimento, e neste aspecto não se obteve resposta por parte dos entrevistados. Destaca-se, ainda, a aplicação do teste de qui-quadrado para estas variáveis, não se observou diferenças significativas a $\mathrm{p}<0,05$ para os grupos ES e EM em relação às variáveis da dimensão "aspirações empreendedoras".

\section{Conclusão}

No Brasil, a taxa de empreendedores sociais é uma 
pequena fração dentro do universo das demais empresas. Os empreendedores sociais se mostraram predominantemente do sexo masculino, acima dos 35 anos, possuem maior nível de escolaridade e operam o negócio em regime de tempo integral. Sobre as dimensões analisadas, em especial, as atitudes e as percepções empreendedoras, afirmaram possuir os conhecimentos e habilidades necessárias para a abertura do empreendimento, além de tratar o empreendimento como opção de careira e possuem menores taxas de medo do insucesso. A dimensão Atividade Empreendedora apresentou maiores taxas de abertura de negócios por empreendedores sociais. A terceira dimensão analisada contemplou Aspirações Empreendedoras, nesta dimensão os empreendedores sociais apresentaram desempenho melhor em relação à taxa de inovação.

Acredita-se que este estudo tenha alcançado o objetivo de contribuir, ainda que inicialmente, com os pesquisadores e demais envolvidos com o campo do empreendedorismo social, em especial, aos pesquisadores brasileiros ao identificar os aspectos que diferenciam os empreendedores sociais dos empreendedores voltados para o mercado, possibilitando o delineamento de estudos futuros sobre a temática apresentada e ampliação da população analisadas, a fim de comparação entre os empreendedores sociais nacionais e os empreendedores dos demais países da América do Sul analisados pelo GEM.

A principal limitação da pesquisa se refere ao baixo número de empreendedores caracterizados como empreendedores sociais, fato este corroborado pelo estudo se restringir a análise dos dados secundários disponibilizados pelo GEM Adult Population Survey (APS) 2015/16, assim como as variáveis analisadas pelo mesmo. Os autores não utilizaram fonte de dados secundários complementares e/ou aplicação de instrumento de coleta de dados primários.

\section{Referências}

ALVORD, S.H.; BROWN, L.D.; LETTS, C W. Social entrepreneurship: leadership that facilitates societal transformation. In: JOHN, F. Working paper. Center for Public Leadership: Kennedy School of Government, 2004.
AUSTIN, J.; STEVENSON, H.; WEI-SKILLERN, J. Social and commercial entrepreneurship: same, different, or both. Entrep. Theory Prat. J., v.30, n.1, p.1-22, 2006.

BOSMA, N. et al. Global Entrepreneurship Monitor: 2008 Executive Report. [S.1.]. 2009.

BOSMA, N. et al. Global Entrepreneurship Monitor 2015 to 2016: Special Report on Social Entrepreneurship. 2016.

CARRAHER, S. M.; WELSH, D. H. B. Global entrepreneurship. Dubuque: Iowa, 2015.

CERTO, S. T.; MILLER, T. Social entrepreneurship: key issues and concepts. Business Horizons, v. 51, p. 267-271, 2008.

COX, A.; HEALEY, J. Promises to the poor: the record of european development agencies. Poverty briefings, London, 1, 1998.

DEES, J.G. The meaning of Social Entrepreneurship, 1998. Disponível em: <http://www.uc.pt/feuc/ceces/ficheiros/dees>. Acesso em: 20 mar. 2020.

FERREIRA, J.J. et al. Conceptualizing social entrepreneurship: perspectives from the literature. International Review on Public and Non-Profit Marketing, v. 14, p. 73-93, 2017.

GEM - Global Entrepreneurship Monitor. Empreendedorismo no Brasil: 2016. Curitiba: IBQP, 2017.

HARDING, R. Social entrepreneurship monitor. London. 2006.

LEPOUTRE, J. et al. Designing a global standardized methodology for measuring social entrepreneurship activity: the Global Entrepreneurship Monitor social entrepreneurship study. Smal Business Economic, 40, 2013. 693-714.

MAIR, J.; MARTÍ, I. Social entrepreneurship research: a source of explanation, prediction, and delight. J. World Business, v.41, p.36-44, 2006.

OLIVEIRA, E. M. Empreendedorismo social no Brasil: atual configuração; perspectivas e desafios - notas introdutórias. Rev. FAE, 7, n. 2, 2004. 9-18.

SEBRAE. Sobrevivência das Empresas no Brasil. São Paulo: Sebrae, 2016.

SZERB, L.; AIDIS, R.; ACS, Z.J. The comparasion of the Global Entrepreneurship Monitor and the Global Entrepreneurship and Development Index Methodologies. Foundations and Trends in Entrepreneurship, 2013.

ZAHRA, S.A. et al. A typology of social entrepreneurs: motives, search processes and ethical challenges. J. Business Venturing, 24, 2009. 519-532. 